\title{
avrPto Enhances Growth and Necrosis Caused by Pseudomonas syringae pv. tomato in Tomato Lines Lacking Either Pto or Prf
}

\author{
Jeff H. Chang, ${ }^{1}$ John P. Rathjen, ${ }^{1}$ Adriana J. Bernal, ${ }^{1}$ Brian J. Staskawicz, ${ }^{1,2}$ and \\ Richard W. Michelmore ${ }^{1,3}$ \\ ${ }^{1}$ NSF Center for Engineering Plants for Resistance Against Pathogens (CEPRAP), University of California, \\ Davis, One Shields Avenue, Davis 95616, U.S.A.; ${ }^{2}$ Department of Plant and Microbial Biology, University \\ of California, Berkeley 94720; U.S.A.; ${ }^{3}$ Department of Vegetable Crops, University of California, Davis \\ 95616, U.S.A. \\ Accepted 2 February 2000.
}

\begin{abstract}
AvrPto was introduced into three tomato genotypes with two biotic agents to study its role in compatible interactions. avrPto enhanced the capacity of the Pseudomonas syringae pv. tomato strain $\mathrm{T} 1$ to induce necrotic symptoms on tomato plants that lacked either Pto or Prf genes. The enhanced necrosis correlated with a small increase in bacterial growth. In planta expression of avrPto in isolation did not elicit necrosis in the absence of a functional Prf gene.
\end{abstract}

Many phytopathogenic bacteria carry avirulence genes. Direct or indirect recognition of avirulence gene products by corresponding host-encoded resistance gene products leads to induction of plant defenses (Flor 1956; Keen 1990; Baker et al. 1997). In the absence of one or both corresponding gene(s), the pathogen escapes recognition and is able to replicate to high levels. Recognition of many bacterial avirulence gene products appears to take place within the host cell (reviewed in Bonas and Van den Ackerveken 1997). In such cases, delivery of the avirulence determinant is dependent on hrp (for hypersensitive response and pathogenicity) genes, which encode a type III protein secretion apparatus (Alfano and Collmer 1997; Lindgren 1997; Hueck 1998; Anderson et al. 1999; Rossier et al. 1999). Evidence is accumulating that bacterial avirulence genes may contribute to fitness in the absence of host resistance (Kearney and Staskawicz 1990; Swarup et al. 1991, 1992; Lorang et al. 1994; Yang et al. 1994; Ritter and Dangl 1995; Jackson et al. 1999). This provides an explanation for the persistence of genes encoding proteins that can lead to the inhibition of bacterial replication if detected by the host.

Pseudomonas syringe pv. tomato (Pst) causes bacterial speck disease on tomato, leading to the formation of small, necrotic flecks surrounded by chlorotic haloes on infected

Corresponding author: Richard W. Michelmore; Telephone: 1-916-7521729; Fax: 1-916-752-9659; E-mail: rwmichelmore@ucdavis.edu

Current address of Jeff H. Chang: Department of Biology CB\#3280, 108 Coker Hall, Chapel Hill, NC 27599. leaves. Strains of Pst that express the avirulence gene avrPto elicit specific disease resistance on hosts carrying the Pto gene. Resistance is manifested as a loss of symptoms at low inoculation levels, or a hypersensitive response (HR) at high bacterial densities. Pto-mediated resistance is dependent on a second host gene, Prf. Mutations in Pto cause a partial loss of avrPto-specific resistance, whereas Prf mutants are completely susceptible (Salmeron et al. 1994). A current model for signal transduction in this system places Pto as the receptor for AvrPto (Scofield et al. 1996; Tang et al. 1996), with Prf coincident or downstream of the recognition event (Rathjen et al. 1999).

avrPto, like certain other avirulence genes, may confer the ability to modify host defense responses. Genomic expression of avrPto from the heterologous pathogen Potato virus $X$ (PVX) conferred avirulence on Pto-expressing plants (Tobias et al. 1999). In contrast, infection of tomato plants lacking either Pto or Prf genes resulted in enhanced necrotic symptoms relative to infections with wild-type PVX (Tobias et al. 1999). Therefore, we investigated whether the presence of avrPto could modify the response of susceptible tomato hosts to Pst infection.

Resistant (Rio Grande 76R [Pto/Pto Prf/Prf]) or nearisogenic susceptible (Rio Grande 76S [pto/pto Prf/Prf]) tomato lines were vacuum infiltrated with $P$ st strains carrying an empty vector (pDSK519) or pDSK519 carrying avrPto (pPtE6; Ronald et al. 1992). Pst T1 carrying empty vector caused typical disease symptoms on both genotypes (Table 1 and Fig. 1). Leaves had multiple necrotic flecks indicative of bacterial speck disease, but otherwise remained green. 76R plants showed few or no disease symptoms in response to Pst T1 expressing avrPto, due to the resistance response mediated by Pto. $76 \mathrm{~S}$ plants infected with Pst T1 (avrPto) exhibited disease symptoms 4 days post inoculation (dpi), and leaves began to dehydrate after $6 \mathrm{dpi}$. This avrPto-dependent effect was examined in completely susceptible plants lacking a functional Prf gene (Rio Grande 76R prf-3 (Pto/Pto prf3/prf3). 76R prf-3 plants infected with Pst T1 developed bacterial speck symptoms similar to $76 \mathrm{R}$ and $76 \mathrm{~S}$ genotypes. 
However, infection of 76R prf-3 plants with Pst T1 (avrPto) resulted in a more rapid and exaggerated response; symptoms began to develop 4 dpi and leaves became black and brittle by 6 dpi (Fig. 1). The increased necrosis in $76 \mathrm{~S}$ plants due to the presence of avrPto is referred to as "enhanced necrosis." The avrPto-dependent increased necrosis in $76 \mathrm{R}$ prf-3 relative to $76 \mathrm{~S}$ is referred to as "severe necrosis." The same severe necrotic phenotype was also observed in Pst T1(avrPto) infections of five other 76R tomato lines with mutations in the Prf gene: prf-4, prf-2, prf-16, prf-19 (Salmeron et al. 1994), and the Prf sense-suppressed line, pSOR-2 (Oldroyd and Staskawicz 1998). Thus, the presence of avrPto appeared to modify the host response to Pst T1 infection, similar to the PVX data (Tobias et al. 1999).

Bacterial growth was measured to determine whether the enhanced necrosis associated with Pst T1(avrPto) infections in susceptible genotypes correlated with increased pathogen replication. $76 \mathrm{~S}$ and $76 \mathrm{R}$ prf-3 plants were vacuum infiltrated with $1 \times 10^{3} \mathrm{CFU}$ per ml of Pst T1 carrying empty vector or avrPto. A small increase in bacterial growth was associated with presence of the avrPto gene. Pst T1 (avrPto) consistently replicated to higher levels than strains lacking avrPto at 4 dpi (Fig. 2A). Parallel differences were observed when plants were vacuum infiltrated with $P s t \mathrm{~T} 1$ at $1 \times 10^{5} \mathrm{CFU}$ per ml (Fig. 2B). The differences in growth were statistically significant $(F=18.57, P<0.001)$ and observed in multiple independent experiments. Bacterial growth was not significantly influenced by plant genotype and the differences in severity of necrosis between $76 \mathrm{~S}$ and $76 \mathrm{R}$ prf-3 did not correlate with differences in bacterial replication.

Expression of avrPto from Pst T1 or PVX caused enhanced necrosis in susceptible tomato hosts. To examine whether induction of necrosis was a primary consequence of AvrPto within the plant cell, we expressed avrPto in planta with Agrobacterium-mediated transient expression. Tomato plants were pressure infiltrated with suspensions of the A. tumefaciens strain $\mathrm{C} 58 \mathrm{C} 1$ carrying either Pto alone, avrPto alone, or both avrPto and Pto together on the same T-DNA (Fig. 3) (Scofield et al. 1996; Rathjen et al. 1999). Expression of wildtype Pto did not elicit an HR in any of the three tomato lines. Co-expression of avrPto and Pto from the same T-DNA elicited an HR in leaves of $76 \mathrm{R}$ and $76 \mathrm{~S}$, but not in leaves of $76 \mathrm{R}$ prf-3. Expression of avrPto alone in 76R leaf tissue elicited an HR due to Pto-mediated recognition. Expression of avrPto in $76 \mathrm{~S}$ tissue caused spotty, nonconfluent tissue collapse within the site of infiltration. In contrast, no effect of avrPto expression was observed in leaves of $76 \mathrm{R}$ prf-3. Therefore, expression of avrPto did not induce necrosis in the absence of a functional Prf gene.

Our data show that expression of avrPto from Pst T1 was associated with an increase in necrotic disease symptoms in susceptible tomato lines. The enhanced necrosis was associated with a slight but significant increase in bacterial replication. However, avrPto did not elicit necrosis when expressed in isolation in the absence of a functional Prf gene. Together, these data show that avrPto is necessary but not sufficient for induction of the pathogen-associated necrosis observed in compatible interactions. avrPto appears to modify the interaction between plant and pathogen leading to an altered host reaction to infection. This may be indicative of suppression of a general defense response, given that the effect was seen with unrelated pathogens. However, the data presented here cannot discriminate whether AvrPto caused its effect within the bacterial or plant cells. Also, we are unable to determine the importance of the Pto gene product in influencing the necrotic phenotype in 76R prf-3, because the extremely tight physical linkage of Pto and Prf precludes generation and analyses of a pto/pto prflprf genotype.

We observed an apparent minor recognition event of avrPto when expressed in wild-type susceptible tomato (76S), as evidenced by development of a limited HR. This observation has been recorded previously (Gopalan et al. 1996), and is consistent with mutational studies in which mutants in the Pto gene were partially resistant to Pst (avrPto) infection, but mutants in Prf were fully susceptible (Salmeron et al. 1994). It is possible that one of the five Pto homologs encoded at the locus mediates this recognition, although no interaction between AvrPto and any of the homologs was detected with yeast two-hybrid analysis (J. Chang, B. Staskawicz, and R. Michelmore, unpublished). It is also possible that Prf itself can act as receptor for AvrPto; however, an interaction between AvrPto and Prf was not necessary for induction of an HR induced by expression of a constitutive gain-of-function mutant of Pto (Rathjen et al. 1999). The implication of a minor avrPto recognition determinant at the Pto locus is interesting because Pst DC3000 encodes a second avirulence determinant that is also recognized by a Prf-dependent process (Ronald et al. 1992; Salmeron et al. 1994). Therefore, the Pto locus appears to determine multiple molecular interactions with Pst.

Table 1. Summary of plant responses to AvrPto delivered by strains of Pseudomonas syringae, Agrobacterium tumefaciens, or Potato virus $X$ (PVX)

\begin{tabular}{|c|c|c|c|}
\hline \multirow[b]{2}{*}{ Biological agent } & \multicolumn{3}{|c|}{ Tomato genotype } \\
\hline & Rio Grande 76R & Rio Grande 76S & Rio Grande 76R prf-3 \\
\hline $\begin{array}{l}\text { P. syringae pv. tomato } \mathrm{T} 1 \text { carrying } \\
\text { vector }\end{array}$ & $\begin{array}{l}\text { Bacterial speck disease } 4 \text { dpi } \\
\text { onward }^{\mathrm{a}}\end{array}$ & Bacterial speck disease 4 dpi onward & Bacterial speck disease 4 dpi onward \\
\hline $\begin{array}{l}\text { P. syringae pv. tomato } \mathrm{T} 1 \mathrm{ex}- \\
\text { pressing avrPto }\end{array}$ & No or very few symptoms 6 dpi & $\begin{array}{l}\text { Disease symptoms } 4 \text { dpi. Necrosis. } \\
\text { Leaves dry but not black as in prf- } 3 \\
\text { plants } 6 \text { dpi }\end{array}$ & $\begin{array}{l}\text { Disease symptoms } 4 \text { dpi. Severe ne- } \\
\text { crosis. Leaves dry and black } 6 \text { dpi }\end{array}$ \\
\hline A. tumefaciens carrying vector & No phenotype & No phenotype & No phenotype \\
\hline A. tumefaciens carrying avrPto & Hypersensitive response $^{\mathrm{b}}$ & Non-confluent HR & No phenotype \\
\hline PVX & Systemic chlorosis & Systemic chlorosis & Systemic chlorosis \\
\hline PVX::avrPto (Tobias et al. 1999) & No macroscopic phenotype & $\begin{array}{l}\text { Varying degrees of tissue necrosis, } \\
\text { from individual leaves to entire plant }\end{array}$ & Necrosis of entire plant \\
\hline
\end{tabular}

\footnotetext{
a dpi, days post inoculation.

${ }^{\mathrm{b}}$ Hypersensitive response.
} 

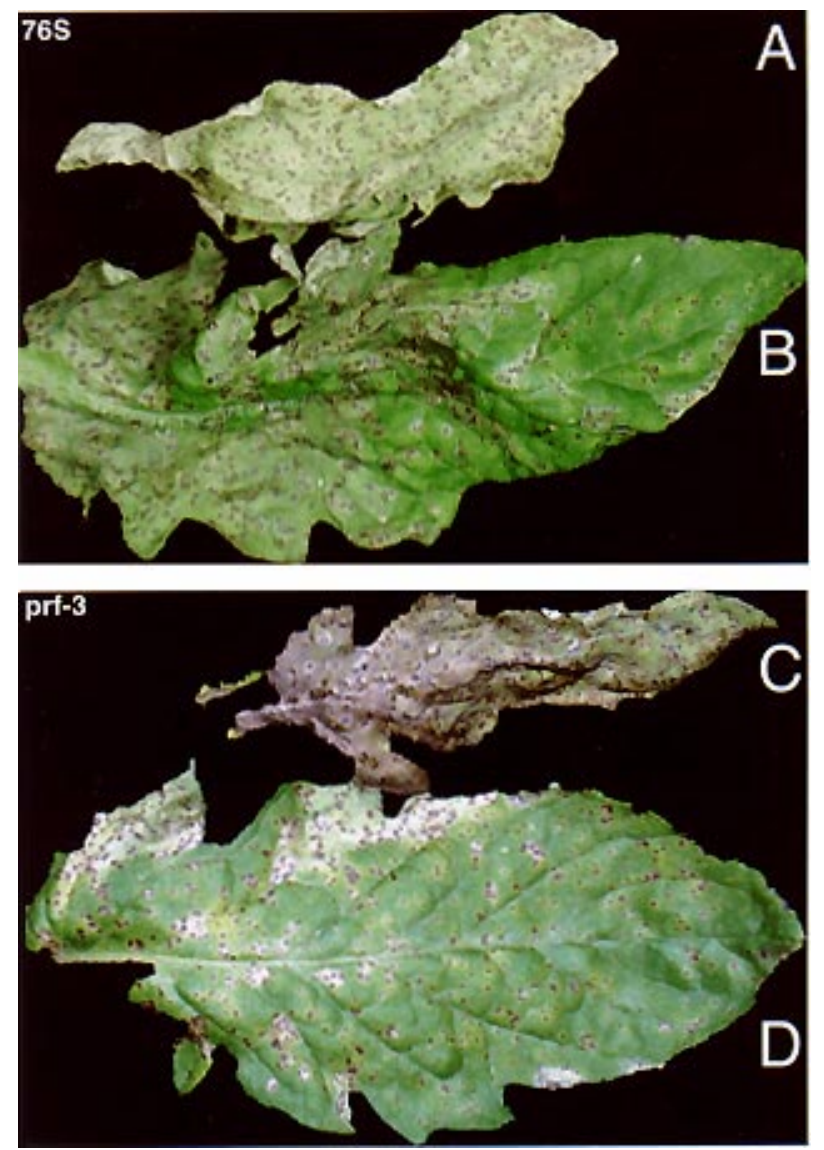

Fig. 1. Pseudomonas syringae pv. tomato T1 expressing avrPto causes enhanced necrosis in plants lacking functional Pto or Prf genes. Depicted are responses by $76 \mathrm{~S}$ and $76 \mathrm{R}$ prf-3 to vacuum infiltration of $1 \times$ $10^{5} \mathrm{CFU}$ per $\mathrm{ml}$ of $P$. syringae pv. tomato expressing (A and $\left.\mathbf{C}\right)$ avrPto or (B and D) pDSK519. Plants were the same age and approximate size at time of infiltration. Leaf pairs ( $\mathbf{A}$ and $\mathbf{C}$, and $\mathbf{B}$ and $\mathbf{D}$ ) were of similar size prior to infiltration and were taken from comparable positions on their respective plants. Photographs were taken 8 days post inoculation.

\section{ACKNOWLEDGMENTS}

We thank Alan Krivanek for assistance on growth curve analysis, Dina St. Clair, Sean Fort, and Doris Chin for advice on statistics, Garry Pearson and Jamie Alvine for plant care, and Pamela Ronald for critical reading of this manuscript. The research was supported by NSF Cooperative Agreement BIR-8920216 to CEPRAP and by CEPRAP corporate associate, Sandoz Seeds.

\section{LITERATURE CITED}

Alfano, J. R., and Collmer, A. 1997. The type III (Hrp) secretion pathway of plant pathogenic bacteria: Trafficking harpins, Avr proteins, and death. J. Bacteriol. 179:5655-5662.

Anderson, D. M., Fouts, D. E., Collmer, A., and Schneewind O. 1999. Reciprocal secretion of proteins by the bacterial type III machines of plant and animal pathogens suggests universal recognition of mRNA targeting signals. Proc. Natl. Acad. Sci. USA 96:12839-12843.

Baker, B., Zambryski, P., Staskawicz, B., and Dinesh-Kumar, S. P. 1997. Signaling in plant-microbe interactions. Science 276:726-733.

Bonas, U., and Van den Ackerveken, G. 1997. Recognition of bacterial avirulence proteins occurs inside the plant cell: A general phenomenon in resistance to bacterial diseases? Plant J. 12:1-7.

Flor, H. H. 1956. The complementary genetic systems in flax and flax rust. Adv. Genet. 8:29-54.

Gopalan, S., Bauer, D. W., Alfano, J. R., Loniello, A. O., He, S. Y., and
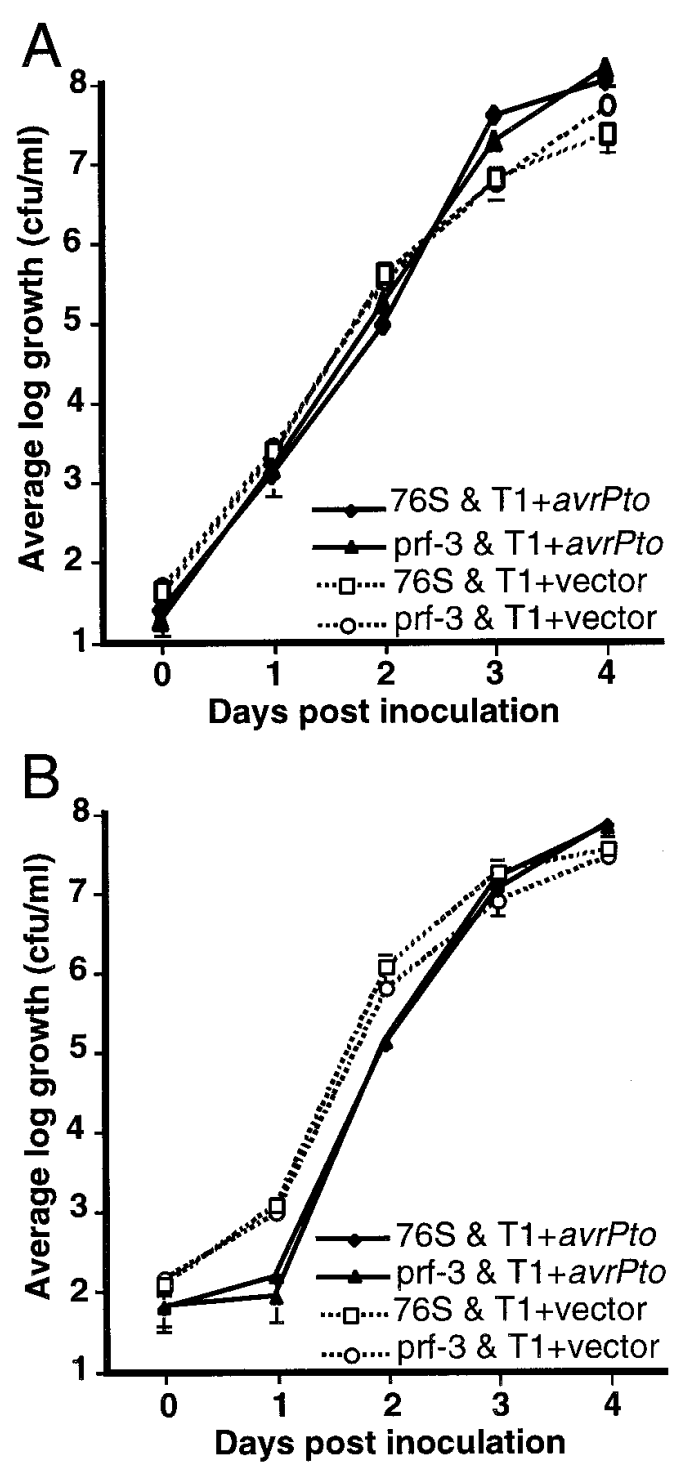

Fig. 2. Multiplication of Pseudomonas syringae pv. tomato T1 in $76 \mathrm{~S}$ and 76R prf-3. P. syringae pv. tomato T1 carrying avrPto or pDSK519 were vacuum infiltrated at $(\mathbf{A}) 1 \times 10^{3} \mathrm{CFU}$ per $\mathrm{ml}$ or $(\mathbf{B}) 1 \times 10^{5} \mathrm{CFU}$ per $\mathrm{ml}$ in $76 \mathrm{~S}$ or $76 \mathrm{R}$ prf-3. Leaf samples were taken daily for 5 days. Data points represent the mean of three leaf samples plus or minus standard error.

Collmer, A. 1996. Expression of the Pseudomonas syringae avirulence protein AvrB in plant cells alleviates its dependence on the hypersensitive response and pathogenicity (Hrp) secretion system in eliciting genotype-specific hypersensitive cell death. Plant Cell 8: 1095-1105.

Hueck, C. J. 1998. Type III protein secretion systems in bacterial pathogens of animals and plants. Microbiol. Mol. Biol. Rev. 62:379-433.

Jackson, R. W., Athanassopoulos, E., Tsiamis, G., Mansfield, J. W., Sesma, A., Arnold, D. L., Gibbon, M. J., Murillo, J., Taylor, J. D., and Vivian, A. 1999. Identification of a pathogenicity island, which contains genes for virulence and avirulence, on a large native plasmid in the bean pathogen Pseudomonas syringae pathovar phaseolicola. Proc. Natl. Acad. Sci. USA 96:10875-10880.

Kearney, B., and Staskawicz, B. J. 1990. Widespread distribution and fitness contribution of Xanthomonas campestris avirulence gene avrBs2. Nature 346:385-386

Keen, N. T. 1990. Gene-for-gene complementarity in plant-pathogen interactions. Annu. Rev. Genet. 24:447-463. 


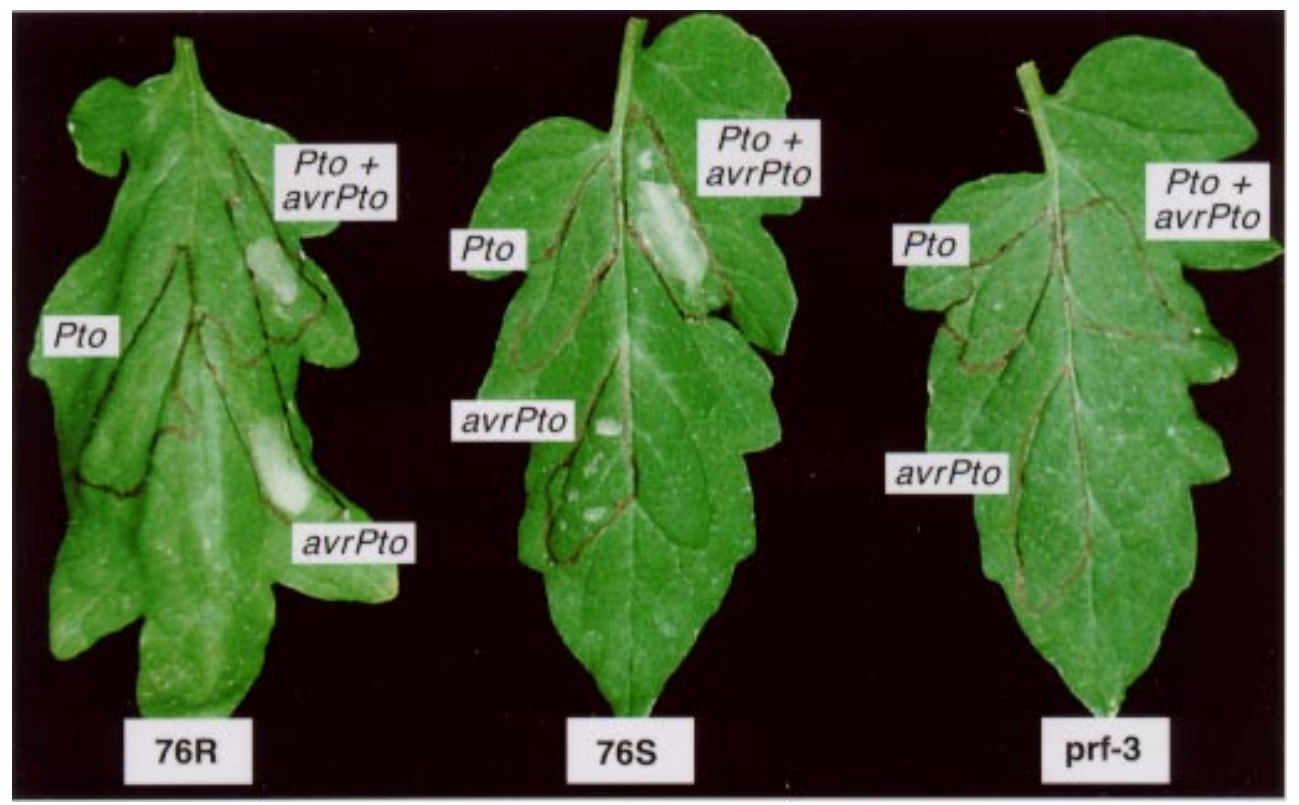

Fig. 3. Agrobacterium-mediated transient expression of Pto, avrPto, and Pto and avrPto together in tomato genotypes 76R, 76S, or 76R prf-3. A. tumefaciens $\mathrm{C} 58 \mathrm{C} 1$ ( $\mathrm{pCH} 30)$ carrying each of the constructs was pressure infiltrated into leaves of 3- to 4-week-old tomato plants. Black lines delineate boundaries of the A. tumefaciens suspension following infiltration. Photographs were taken 2.5 days post inoculation. Results are representative of at least three separate infiltrations.

Lindgren, P. B. 1997. The role of $h r p$ genes during plant-bacterial interactions. Annu. Rev. Phytopathol. 35:129-152.

Lorang, J. M., Shen, H., Kobayashi, D., Cooksey, D., and Keen, N. T. 1994. avrA and avrE in Pseudomonas syringae pv. tomato PT23 play a role in virulence on tomato plants. Mol. Plant-Microbe Interact. 7: 508-515.

Oldroyd, G. E. D., and Staskawicz, B. J. 1998. Genetically engineered broad-spectrum disease resistance in tomato. Proc. Natl. Acad. Sci. USA 95:10300-10305.

Rathjen, J. P., Chang, J. H., Staskawicz, B. J., and Michelmore, R. W. 1999. Constitutively active Pto induces a Prf-dependent hypersensitive response in the absence of avrPto. EMBO J. 18:3232-3240.

Ritter, C., and Dangl, J. L. 1995. The avrRpml gene of Pseudomonas syringae pv. maculicola is required for virulence on Arabidopsis. Mol. Plant-Microbe Interact. 8:444-453

Ronald, P. C., Salmeron, J. M., Carland, F. M., and Staskawicz, B. J. 1992. The cloned avirulence gene avrPto induces disease resistance in tomato cultivars containing the Pto resistance gene. J. Bacteriol. 174: 1604-1611.

Rossier, O., Wengelnik, K., Hahn, K., and Bonas, U. 1999. The Xanthomonas Hrp type III system secretes proteins from plant and mammalian bacterial pathogens. Proc. Natl. Acad. Sci. USA 96:9368-9373.

Salmeron, J. M., Barker, S. J., Carland, F. M., Mehta, A. Y., and Staskawicz, B. J. 1994. Tomato mutants altered in bacterial disease resistance provide evidence for a new locus controlling pathogen recogni- tion. Plant Cell 6:511-520.

Scofield, S. R., Tobias, C. M., Rathjen, J. P., Chang, J. H., Lavelle, D. T., Michelmore, R. W., and Staskawicz, B. J. 1996. Molecular basis of gene-for-gene specificity in bacterial speck disease of tomato. Science 274:2063-2065.

Swarup, S., De Feyter, R., Brlansky, R. H., and Gabriel, D. W. 1991. A pathogenicity locus from Xanthomonas citri enables strains from several pathovars of $X$. campestris to elicit canker-like lesions on citrus. Phytopathology. 81:802-809.

Swarup, S., Yang, Y., Kingsley, M. T., and Gabriel, D. W. 1992. An Xanthomonas citri pathogenicity gene, pthA, pleiotropically encodes gratuitous avirulence on nonhosts. Mol. Plant-Microbe Interact. 5: 204-213.

Tang, X., Frederick, R. D., Zhou, J., Halterman, D. A., Jia, Y., and Martin, G. B. 1996. Initiation of plant disease resistance by physical interaction of AvrPto and Pto kinase. Science 274:2060-2063.

Tobias, C. M., Oldroyd, G. E. D., Chang, J. H., and Staskawicz, B. J. 1999. Plants expressing the Pto disease resistance gene confer resistance to recombinant PVX containing the avirulence gene AvrPto. Plant J. 17:41-50.

Yang, Y., Feyter, R., and Gabriel, D. W. 1994. Host-specific symptoms and increased release of Xanthomonas citri and X. campestris pv. malvacearum from leaves are determined by the 102-bp tandem repeats of $p t h A$ and avrb6, respectively. Mol. Plant-Microbe Interact. 7: 345-355. 